\title{
Structure Erection Technology for PAR Modules of Ichthys Onshore LNG Project
}

\author{
Tui Deng
}

\begin{abstract}
The Ichthys LNG Project, one of the world's largest LNG developments, involves gas from the Ichthys Field in the Browse Basin off north-west Australia being exported to the onshore processing facilities in Darwin via an $889 \mathrm{~km}$ pipeline. This project consists of 2 identical trains, one train of Ichthys PAR shall be fabricated as a whole structure and high accuracy shall be achieved in erection phase. It brings big challenge to erection work of these modules. Reasonable structure erection technology ensures good performance of fabrication activities. This paper presents mainly the structure erection technology for PAR modules of Ichthys Onshore LNG Project and also discusses special problems associated with the erection process including the erection sequence, the foundation settlement control, the method for dimensional control etc. The presented experience will benefit the construction of future modular construction.
\end{abstract}

Index Terms-Dimension control, erection, LNG, structures.

\section{ABbreviation:}

\begin{tabular}{|c|c|}
\hline \multirow{2}{*}{\multicolumn{2}{|c|}{$\begin{array}{l}\text { LNG = Liquefied Natural Ga } \\
\text { PAU= Pre-assembled Unit }\end{array}$}} \\
\hline & \\
\hline PAR & $=$ Pre-assembled Rack \\
\hline SPMT & $=$ Self-Propelled Modular Trailers \\
\hline COOEC & $=$ China Offshore oil eng \\
\hline & =Welding Procedure Specification \\
\hline
\end{tabular}

\section{INTRODUCTION}

Modular construction is a well-proven technique for the Onshore LNG industry and is often preferred because of site conditions and cost saving [1].

Steel structures for LNG facility are usually separated into three types: 1. PAR: Modular structures that will be built in a construction yard out of site (pre-assembled Rack); 2. PAU: Modular structures that will be built in a construction yard out of site (pre-assembled Unit); "Stick-built" structures: built at site structures and 3. SPP: Pre-assembled structures at Site, and then transported by SPMT to their final position [2].

The Ichthys LNG Project, one of the world's largest LNG developments, involves gas from the Ichthys Field in the Browse Basin off north-west Australia being exported to the onshore processing facilities in Darwin via an $889 \mathrm{~km}$ pipeline.

COOEC, as one of the Fabricators of Ichthys LNG Project is responsible for the construction of the PAR modules of Ichthys Project Onshore LNG Facilities.

Manuscrpt received February 20, 2017; revised March 20, 2017

Tui Deng is with the Offshore Oil Engineering co., LTD, CO 266520 China (e-mail: dengt@mail.cooec.com.cn).
The process pipes for one train are connected integrally as a whole in final position. In order to ensure the accuracy of the pipe installation, it is required to adopt integratedconstruction method for each train, ie. all of the pipes in one train shall be installed the same as final status and then be cold cut between 2 adjacent modules after pressure test for the whole train and before transported by vessel. That means each train shall be fabricated as a whole structure and high accuracy shall be achieved in erection phase. The total weight of these LNG PAR modules is approximately 32000 tons. These LNG PAR modules mainly consist of 2 identical trains, each train includes 4 modules respectively, each module weights up to 6000 tons. Each train has a length of about $360 \mathrm{~m}$, a width of $48 \mathrm{~m}$ as shown in Fig. 1.

Because the modules of $360 \mathrm{~m}$ are fabricated in a whole, the elevation difference for the bottom surface of all of the columns shall be restricted within $\pm 3 \mathrm{~mm}$ during fabrication as per project requirement. It brought huge challenge to dimensional control. How to design the stools to minimize the negative impact of foundation settlements? How to achieve the target elevation difference for the bottom surface of all of the columns before erection? How to optimize the erection sequence? How to make sure the dimension requirement in the process of erection can meet the project requirement?

The following sections will answer these questions and present the structure erection technology successfully applied in PAR module fabrication.

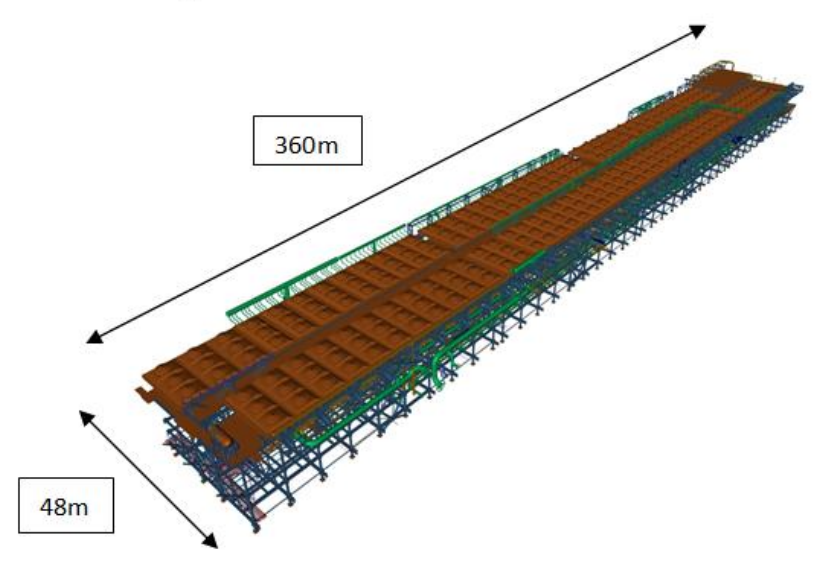

Fig. 1. Overview for PAR modules.

\section{FABRICATION STOOL DESIGN}

During construction, the stools are used under the columns as temporary supports. The wind force shall be considered in stools design. For the temporary structure, the serving period of the stool is 2 years, the design period is 5 years. According to the design standard [3], the wind velocity shall be selected 
for five-year return period

Each module's support reactions shall be provided by detail design party. The maximum value of the force at the state of test and erection is used in the design of the stools and weighing stools.

The reaction of the column can be divided into two types, which are horizontal force and vertical force. Stools are to be designed according to the reactions and the foundation bearing capacity. Stability including overturning, sliding and soil pressure shall be checked in accordance with the design load and soil bearing capacity. Leg size of fillet weld chose $70 \%$ of thickness of bracing plate, which can meet the requirement of AISC [4]. Please refer to the Fig. 2 for the design method of the stools.

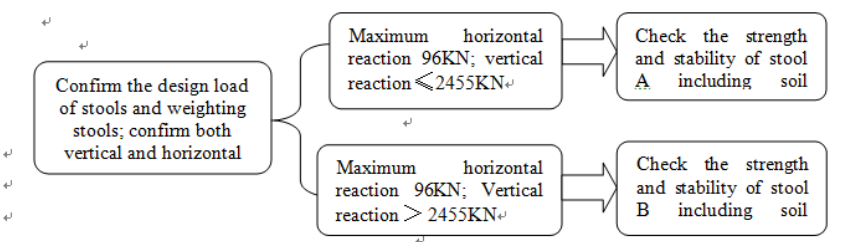

Fig. 2. Design method for stools.

\section{GROUND LEVELLING AND FABRICATION STOOL LAYOUT}

Fabrication shall proceed on a flat level surface. Frequent level checks shall be performed. When any column or horizontal member settles more than tolerance, the settled column or horizontal member shall be shimmed back into a level plane. The differential elevations between module stool points shall be restricted to $3 \mathrm{~mm}$.

The detailed method to level the stool ground by placing concrete and grout under stools is as following:

Regolith shall be removed under the stool layout area (for concrete platform, the surface shall be cleaned) which shall be $100 \mathrm{~mm}$ protruded out from the stool base plate. The detail is shown in Fig. 3. Concrete shall be placed and cured first, certain gap between the top surface and the bottom surface of stool shall be achieved for ease of grout flowing, the stool shall be located on the target position by means of shimming. Concrete surface shall be blasted and wetted 24 hours before placing the grout to ensure a good bond between foundation concrete and grout material. Grouting and curing shall be performed after that.

The detailed work flow is as following,

1) Treat the construction area by dynamic compaction.

2) Clear and make the construction area flat prior to levelling.

3) Set up datum point. After that, all areas for stool laying shall be surveyed. The survey result will be the basis for choosing levelling method.

4) Clear the ground surface: Regolith shall be removed by digging shallow pit which shall be $100 \mathrm{~mm}$ protruded out from the stool base plate. Clear the pit and compact the pit bottom. Re-measure according to the datum point, mark $0 \mathrm{~mm}$ elevation at the location.

5) Arrange horizontal line in accordance with the $0 \mathrm{~mm}$ elevation position to establish $0 \mathrm{~mm}$ elevation datum as target surface.

6) Place support frame for concrete.
7) Prepare concrete: concrete strength shall not be less than C35.

8) Place concrete, vibrate and roll steel drum on its surface.

9) Concrete curing.

10) Blast and water soak concrete surface. All concrete surface shall be thoroughly cleaned and wetted prior to placing the grout to ensure a good bond between foundation concrete and grout material.

11) Place the stool on the target position by means of shimming. The level check of surface shall be performed using gradienter and the differential elevations between top surfaces of stools shall be restricted to $6 \mathrm{~mm}$. If the tolerance exceeds $\pm 3 \mathrm{~mm}$, adjustment shall be made by means of shimming.

12) Place support frame for grout

13) Grout.

14) Perform maintenance
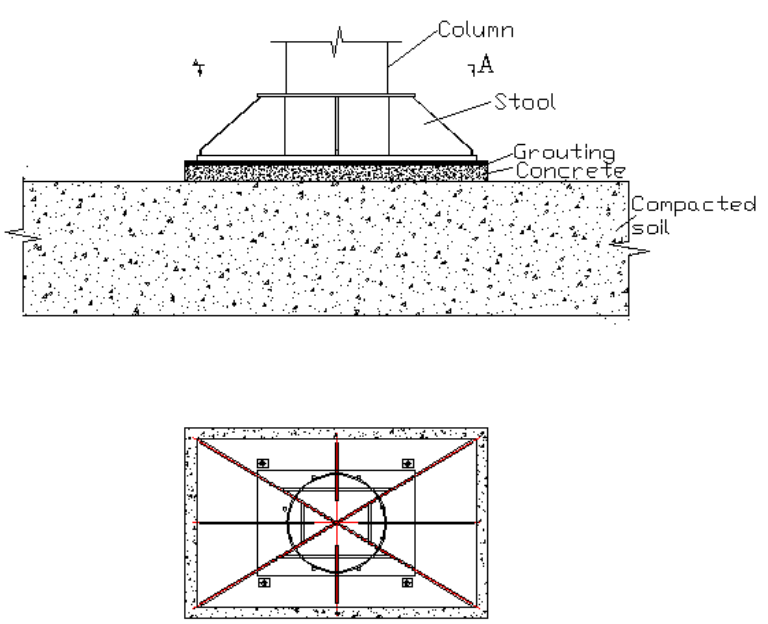

SECTION A-A

Fig. 3. Details for levelling for stools.

Further adjustment method is as following:

15) The final level (with $+/-3 \mathrm{~mm}$ tolerance) can be further adjusted by using the shim plates inserted between module column base plate's bottom of steel (BOS) and the stool's top of steel (TOS).

16) Shim plates thickness shall be no greater than $10 \mathrm{~mm}$ each and maximum of four pieces shim plates can be used at the same time providing $40 \mathrm{~mm}$ maximum total shim plate height.

17) In no case the columns could contact with the unpainted shim plates/chocks. Unless otherwise noted, chocks/shim plates located at bottom of column base shall be blasted and painted. The edges distance between the column base to shim plates shall have at least $20 \mathrm{~mm}$. The edge distance from the shim plates to stool top of steel plate shall be at least $10 \mathrm{~mm}$. Bearing contact area between the column base plate and the shim plate shall be no less than $90 \%$ of the column base plate.

18) After field erection commences, workers will monitor the position of the stools periodically to ensure that they remain within tolerance. When there is settlement of stools outsides tolerance, it should be reported and remedial action shall be undertaken immediately. 


\section{SOLUTiOn TO Foundation SETTLEMENT}

The settlement monitoring and checks of level shall be made on a weekly basis. If unequal settlement occurs and structure inclines to one side, the erection work shall stop immediately. The settled section shall be brought back into level by jacking up the structure and then correct it by shimming. Misalignment shall be corrected at all stages of erection. The specific procedure is as specified in Fig. 4

Requirement for jacking up operation is listed as following:

1) Unfixed and loose items in structure shall be removed before jacking up. The ground around shall be cleared.

2) Foundation bearing capacity must be calculated and verified to ensure that the foundation bearing capacity can meet requirements.

3) During the jacking up work, any obstacle within $10 \mathrm{~m}$ radius of work point is not permitted.

4) Personnel shall be kept away from work point and kept within safety zone.

5) Jacking work shall be carried out during daylight hours.

The method for adjustment after settlement is as following:

Arrange one assembly stool underneath each column during fabrication. Arrange two jacks and stool adjacent to the column where unequal settlement occurs. Jack up the structure if the load of jack is within the rated capacity (Note: calculation shall be done to verify if member strength can withstand such load). In case of the load of jack exceeding the rated capacity, jacking up can be done by jack in conjunction with Synchronous Jacking System, then insert shim between the column and assembly stool to compensate the settlement. If equal settlement occurs and has no impact to erection and further work, more intensified investment and monitoring shall be conducted. Once inclining occurs, remedial action shall be undertaken immediately.

Note: It shall be ensured that the survey line does not move during erection.

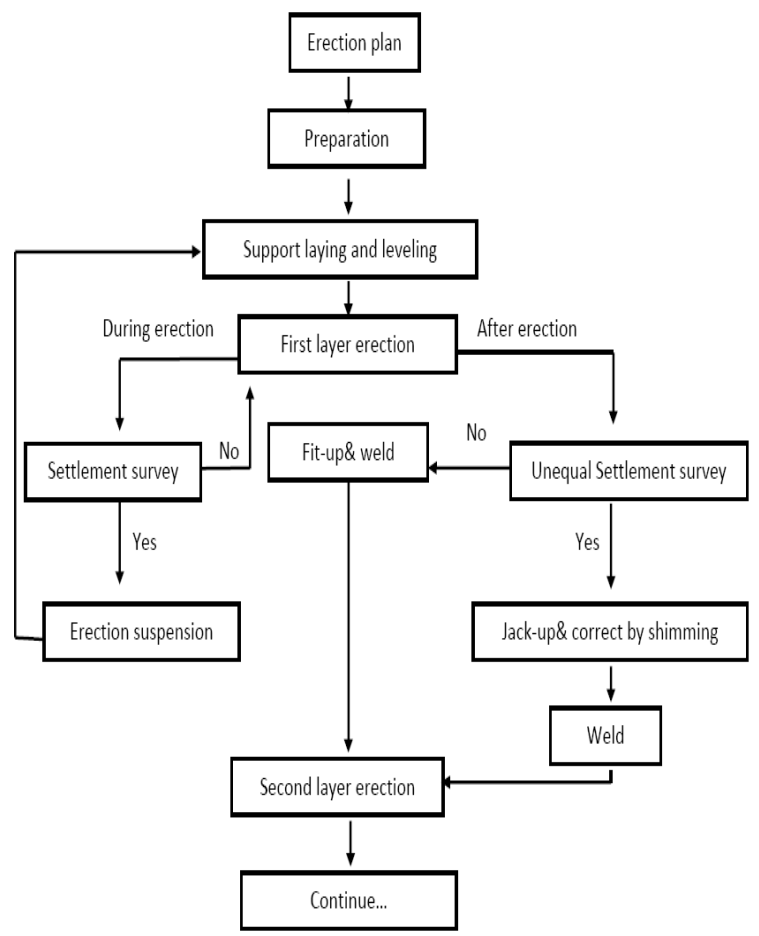

Fig. 4. Work flow of solution to foundation settlement.

\section{FABRICATION SEQUENCE CONSIDERATION}

For the general work flow chart for fabrication activity, please refer to Fig. 5.

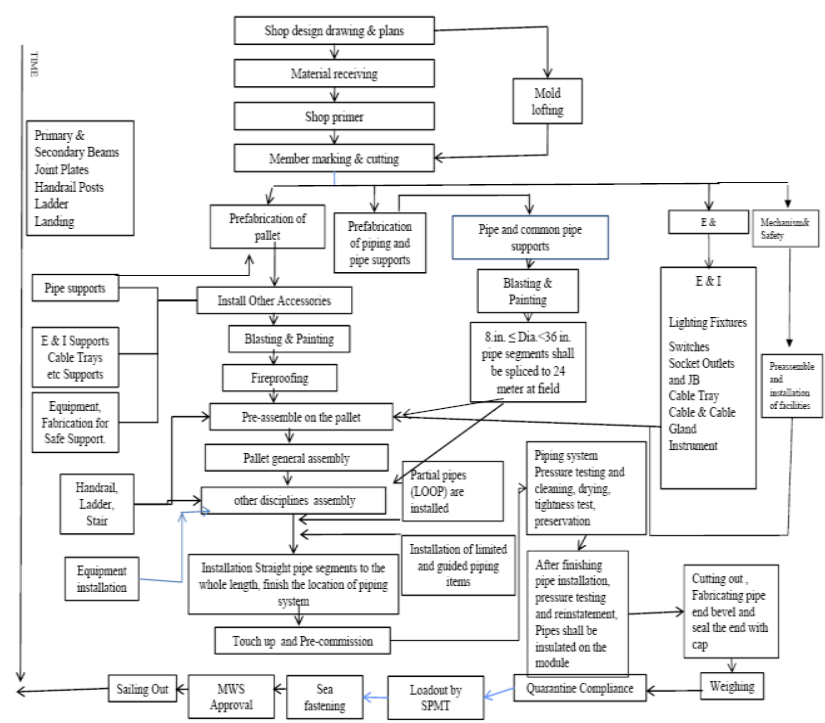

Fig. 5. Fabrication work flow.

It can be discerned from Fig. 5 that a lot of activities in other disciplines are involved in the fabrication process. Therefore a reasonable erection sequence shall be studied carefully to ensure high efficiency with high quality [5]-[7].

One typical module is as shown in Fig. 6. Each level of structure shall be divided in to several pallets according to the crane capacity and erection schedule. The Pallets break for one typical module is as shown in Fig. 7.

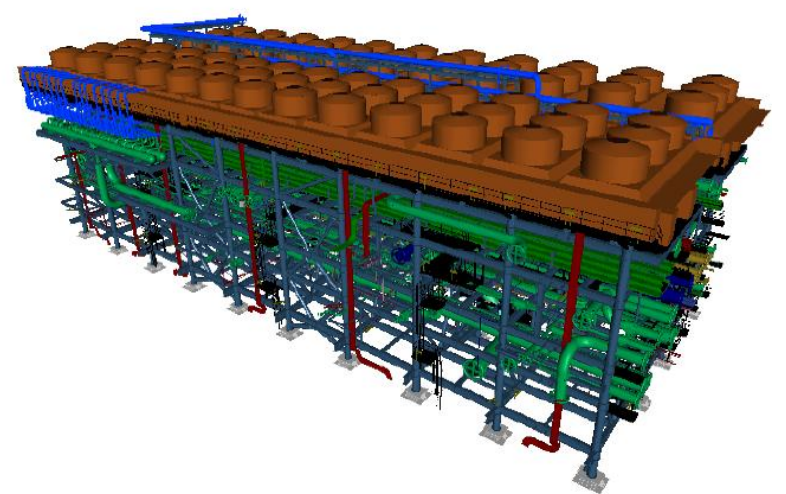

Fig. 6. Image of one typical module.

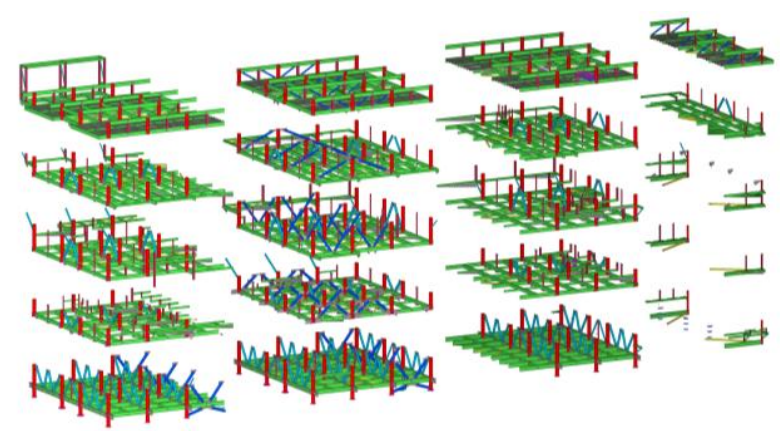

Fig. 7. Pallets break for one typical module.

Each pallet will be lifted and erected by crane, each crane load shall be confirmed to be lower than the minimum safety 
work requirement. Gantry crane load shall be lower than $80 \%$ of its rated lifting capacity. Single crane load shall be lower than $90 \%$ of its rated lifting capacity. In the condition of two cranes associated loading, each crane load shall be lower than $80 \%$ of its rated lifting capacity. In the condition of more than two cranes associated loading, each crane load shall be lower than $75 \%$ of its rated lifting capacity [8]. The safety factor of the chosen sling shall be 4.0. The safety factor of the chosen shackling shall be 3.0. The actual lifting weight = theory weigh* Weight factor *Dynamic Amplificatory Contingency.

The lifting locations shall be studied well to ensure both safety and cost-saving [9].

Only certified rigging equipment and cranes can be used on the project. The dynamic amplificatory contingency of large structures conforms to requirements of DNV standard. DNV Dynamic Amplification Factors are shown as Table I [10].

TABLE I: SELECTION OF DYNAMIC AMPLIFICATION FACTORS

\begin{tabular}{|l|c|c|c|}
\hline $\begin{array}{c}\text { Static-Hook } \\
\text { Load }\end{array}$ & $\begin{array}{c}\text { DAF } \\
\text { Onshore }\end{array}$ & $\begin{array}{c}\text { DAF } \\
\text { Inshore }\end{array}$ & $\begin{array}{c}\text { DAF } \\
\text { offshore }\end{array}$ \\
\hline $50-100 \mathrm{t}$ & 1.10 & 1.15 & 1.30 \\
\hline $100-1000 \mathrm{t}$ & 1.05 & 1.10 & 1.20 \\
\hline $1000-2500 \mathrm{t}$ & 1.05 & 1.05 & 1.15 \\
\hline$>2500 \mathrm{t}$ & 1.05 & 1.05 & 1.10 \\
\hline
\end{tabular}

\section{ALIGNMENT FOR PALLETS ERECTION}

The alignment for pallet erection is very important for the dimensional control. Following method is developed to make sure the dimension can meet project requirement after erection.

Step 1: Before the alignment of upper pallet, the horizontal baseline of the lower pallet columns shall be adjusted accurately using gradienter and total station. Any inaccuracy out of tolerance shall be corrected by minor adjustment or relocating if necessary. The detail is as shown in Fig. 8.

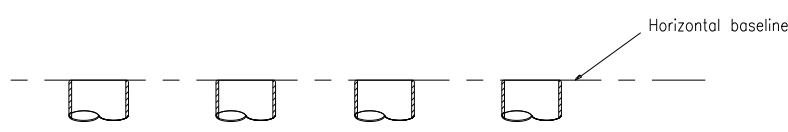

Fig. 8. Adjust the horizontal baseline.

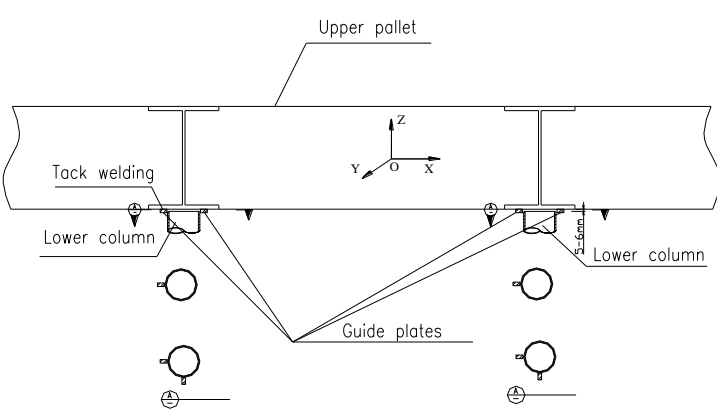

Fig. 9. Put down the upper pallet.

Step 2: Put down the upper pallet. There are many location points of incoming members already marked before alignment in the upper pallet, footprint areas to be ground to bright clean metal before assembly of pallets and six guide plates shall be tack welded under the chosen upper pallet primary beams, for details see Fig. 9. The purpose of these guide plates is to assist the crane to put down the pallet to the specific location.

Step 3: Install 3 Guide Plates with tapered lead in edges for weld access at 120 degree intervals onto the underside of the upper pallet nodes. For details see Fig. 10 and the Guide Plates are not welded to any component. The purpose of these plates is to adjust the Z-axes position of the upper pallet and to achieve the required root gap.

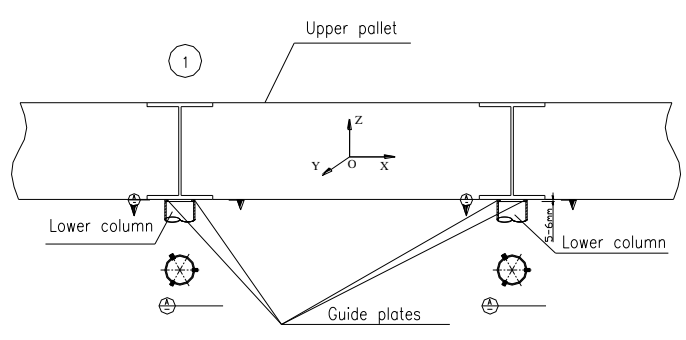

Fig. 10. Insert three guide plates.

Step 4: Install 3 spacer plates for weld access at 120 degree intervals onto the top of the tubular column. These plates shall project by $3-5 \mathrm{~mm}$ to maintain the root gap after erection, as per the applicable WPS, for details see Fig. 11.

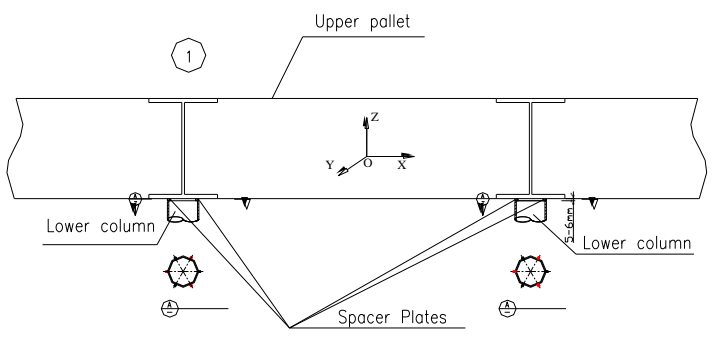

Fig. 11. Insert three spacer plates.

Step 5: After the accurate orientation of the upper pallet, the upper beam and lower column shall be tack welded. For each welding position, at least 3 tack welds shall be applied and the length of each shall be over $50 \mathrm{~mm}$. For details see Fig. 12. Dimensional survey shall be conducted after tack welding.

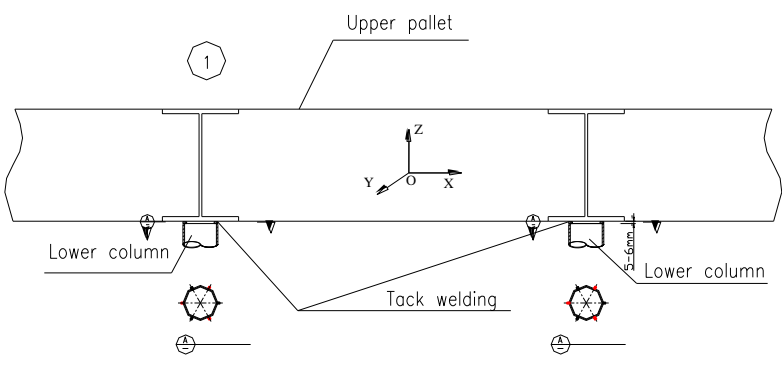

Fig. 12. Tack welding

Step 6: After tack welding, dimension inspection and visual inspection shall be implemented by QC. All of the Guide Plates shall be taken away by hammer knocking before release of cranes.

Step 7: Full welding shall be performed and cranes can be 
released after one third of all joints have been welded. For details see Fig.13.

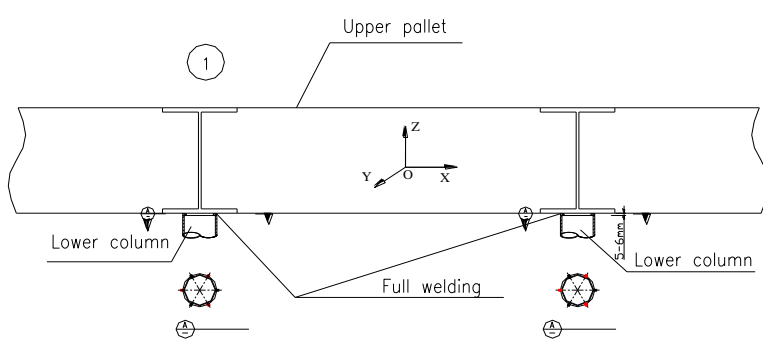

Fig. 13. Full welding.

\section{CONCLUSION}

The fabrication work of PAR modules was challenging. Reasonable structure erection work-flow and sequences ensure good performance of fabrication activities. The structure erection technology is undoubtedly playing key roles for the successful execution of the project. Considerations to address ground bearing capacity limit, foundation settlement control, dimension control, erection sequence and alignment have been proven as good practices. In general, erection technology of the PAR modules will benefit future similar structure fabrication.

\section{REFERENCES}

[1] S. S. K. Wong, A. Shive, and H. Warren, "Weight management considerations for onshore modularized petrochemical facilities," Structures Congress 2011 @ ASCE 2011, pp. 2458-2472, 2011.

[2] T. Deng, Y. F. Zhang, and S. H. Xu, "Fabrication considerations for PAR modules of large onshore LNG project," in Proc. the 11th Pacific Structural Steel Conference, pp. 1169-1174, 2016.

[3] Unified standard for reliability design of building structure, GB50068.
[4] Code of Standard Practice for Steel Buildings and Bridges, AISC 303

[5] Activities in Modular Construction, Proceedings of the 10th East Asia-Pacific Conference on Structural Engineering \& Construction, Bangkok, Thailand.

[6] S. H. Ainslie, P. D. Burns, and R. J. Clark, "Modularization techniques and structural steel procurement on OPTI-NEXEN'S long lake upgrader project," in Proc. the 33rd Annual General Conference of the Canadian Society for Civil Engineering, Ontario, Canada, 2005.

[7] W. Bounds, "Structural engineering challenges designing modules for the Sakhalin I project," presentation at the Structural Engineers Association of Texas, Houston, Texas, 2005.

[8] D. Wu, Y. S. Lin, X. Wang, and X. K. Wang, "Design and realization of crawler crane's lifting simulation system," in Proc. the ASME 2008 International Design Engineering Technical Conferences \& Computers and Information in Engineering Conference, Brooklyn, New York, vol. 3, parts A and B, pp. 1523-1531, 2008.

[9] S. Rajasekaran, D. Annet, and Y. S. Choo, "Optimal locations for heavy lifts for offshore platforms," Asian Journal of Civil Engineering (Building and Housing), vol. 6, pp. 605-627, 2008

[10] DNV-157 Rules for Planning and Execution of Marine Operations.

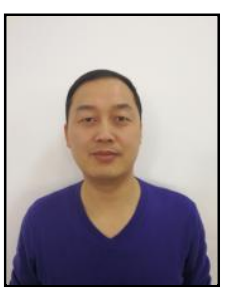

Tui Deng was born in Hubei province of China on 1984. He was graduated in 2010 from Dalian University of Technology with master degree in coastal and offshore engineering. Mr Deng is engaged in structure fabrication research in China Offshore Oil Engineer Corporation(COOEC).

He has already achieved much experience in field engineering and construction. He ever took part in international LNG projects as structure engineer such as ICHTHYS LNG project and deputy leader structure engineer for YAMAL LNG project. By now, he has presided over the editing of Series of technical documents including structure field engineering and construction. For long time, he always focus on structure construction techniques.

Tui Deng was ever awarded best employee of COOEC(Qingdao) for his excellent performance in structure engineering and construction. At the same time, engineering team for YAMAL prioject led by Mr Deng was rated one of the best group of COOEC. 